УДК 93/94

\title{
ЛЕОНАРДО ДА ВИНЧИ И ЕГО ЗАРИСОВКИ СКЕЛЕТНОЙ СИСТЕМЫ
}

\author{
Кузнецова Полина Игоревна \\ студент \\ Научный руководитель: Панова Евгения Львовна \\ к.ф.н., доцент кафедры истории медицины \\ Российский университет дружбы народов
}

Аннотация: Леонардо да Винчи (1452-1519) известен как гениальный итальянский художник, ученый и анатом эпохи Возрождения. Он был одним из первых, кто выполнил точные изображения систем человеческих органов, сопроводив их пояснительными примечаниями. Леонардо да Винчи принадлежит первенство в точном изображении пропорций всех частей человеческого скелета: правильного строения тел позвонков в их сочленениях, S-образной структуры позвоночника при грудном кифозе и поясничном лордозе. Его изображения скелетной системы были высокого качества и демонстрируют изменение мировоззрения и научного взгляда на человека в период Раннего Нового времени.

Ключевые слова: Леонардо да Винчи, скелетная система, позвонки, позвоночник, история анатомии.

\section{LEONARDO DA VINCI AND HIS DEPICTIONS OF SKELETAL SYSTEM}

\section{Kuznetsova Polina Igorevna Panova Evgenia Lvovna}

\begin{abstract}
Leonardo da Vinci (1452-1519) is known as a genius Italian artist, scientist and anatomist of the Renaissance. He was one of the first to make accurate images of human organ systems accompanied by explanatory notes. Leonardo da Vinci holds the primacy in accurately depicting the proportions of all parts of the human skeleton: the correct structure of the vertebral bodies in their joints, the Sshaped structure of the spine in thoracic kyphosis and lumbar lordosis. His images
\end{abstract}


of the skeletal system were of high quality and demonstrate the change of the worldview and scientific view of human during the Early Modern period.

Key words: Leonardo da Vinci, the skeletal system, vertebrae, spine, history of anatomy.

Леонардо да Винчи (1452-1519) - гениальный итальянский ученый, величайший анатом и художник, который сделал поразительно точные изображения систем человеческих органов эпохи Возрождения [1]. В стремлении к реалистичному изображению человека, он был одним из немногих исследователей того времени, изучавших человеческое тело с помощью вскрытия трупов людей, тем самым развивая научную анатомию [1]. Леонардо да Винчи, прежде всего, уделял большое внимание изучению опорно-двигательного аппарата, сопровождая его изображения пояснительными примечаниями. Одним из главных достижений Леонардо да Винчи в анатомии является создание уникальных анатомических рисунков, которые в настоящее время используются в качестве наглядных изображений в учебниках анатомии. Леонардо - первый научный иллюстратор анатомии. Он считал, что без рисунка нет анатомической науки и что слова не могут передать форму и строение органа так ясно, как это можно сделать с помощью рисунка [2].

Леонардо да Винчи выполнил большое количество анатомических рисунков всех систем органов, но особенное внимание уделил опорнодвигательному аппарату. Художник изображал чёткие анатомические зарисовки скелета человека [1]. Да Винчи удивительно точно отразил пропорции скелета человека, которые ранее изображались только схематично. Считается, что Леонардо был первым в истории, кто точно проиллюстрировал позвоночник, поскольку смог передать его изгибы: лордозы и кифозы, а также позвонки, плотно примыкающий друг к другу и угол наклона крестца [3]. Ученый также обозначил точное количество позвонков, разделив их на отделы. Отдельно можно найти изображения шейного отдела: первый позвонок (атлант), второй (осевой позвонок), третий позвонок [4]. Кроме того, он заметил, что крестец состоит из пяти позвонков, а не из трех, как считали ранее [3]. Леонардо использовал знания архитектуры и математики для того, чтобы понять и правильно изобразить строение человеческого тела. Ему свойственна удивительно точная передача структуры позвоночника, которую 
можно сравнить с современными технологиями: магнитно-резонансной томографией и компьютерной томографией.

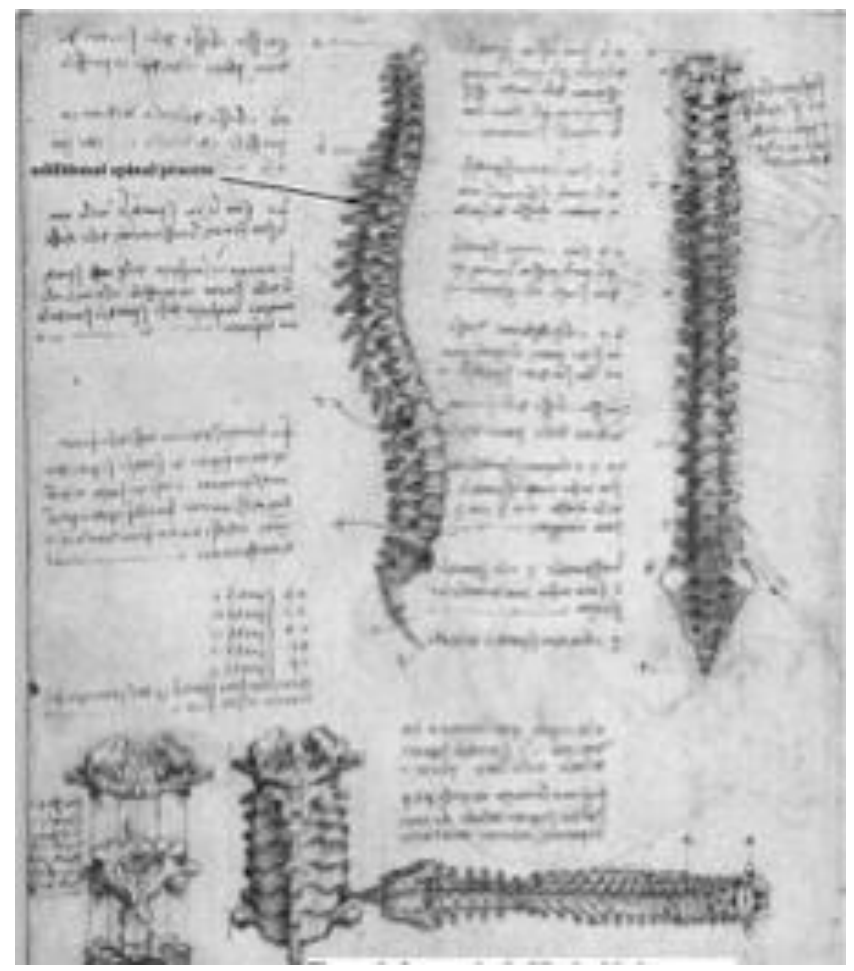

Рис. 1. Леонардо да Винчи: передний, задний и боковой вид позвоночного столба, задний вид шейных позвонков. Коллекция Ее Величества Королевы в Виндзорском замке [5]

Изучая скелет человека, Леонардо сделал вывод о строении костей: «...ради анатомии костей, которые нужно распилить и показать, какая полая и какая нет, которая мозговая и которая губчатая, и которая снаружи внутри толста и которая тонка, а иная имеет в некоем месте большое истончение, а в ином толста и в ином полая или заполнена костью, мозговая или губчатая». Этому правилу он и следовал, исследуя кости верхнего и нижнего пояса конечностей. Так, он сделал шесть набросков: плечевой пояс - вид сзади, туловище с позвоночником - вид сбоку, тазовые кости, туловище - вид спереди, место сочленения тазовых костей с костями ног - вид сбоку и отдельно кости ног - вид сбоку. Изучая кости трупа, да Винчи описал лопатку в верхнем, переднем, боковом, заднем виде, плечевую кость, восемь настоящих ребер и мечевидный отросток с грудиной - все они были изображены в сочленении с другими костями [5]. 


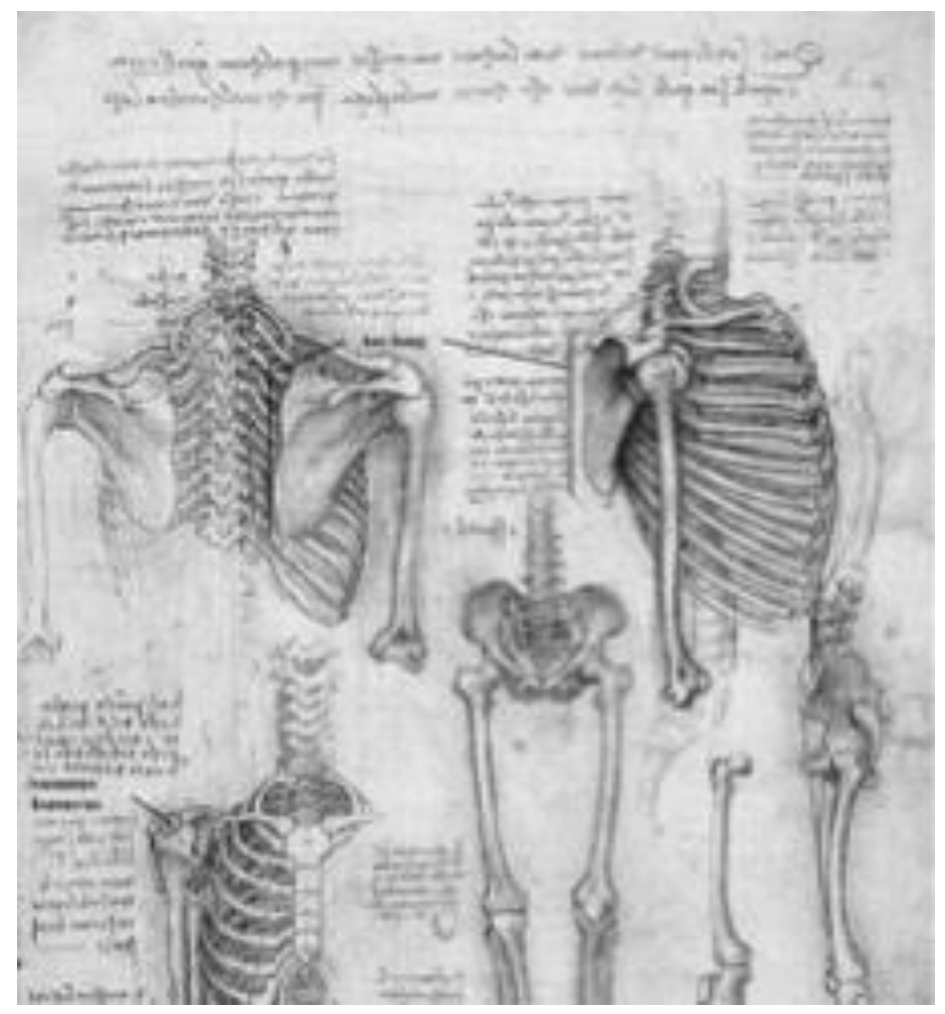

Рис. 2. Леонардо да Винчи: передний, задний и боковой вид грудной клетки и грудного пояса, передний и боковой вид костей нижней конечности. Коллекция Ее Величества Королевы в Виндзорском замке [5]

Также Леонардо сделал анатомические заметки с серией рисунков с подробными набросками черепа. Для этого он аккуратно срезал с трупа переднюю часть лица, не повреждая кости. Один из этих рисунков черепа назывался "Череп с разрезом" [6]. На нем Леонардо исследовал положение лицевых полостей по отношению к поверхности, в левой части зарисовки да Винчи описал форму и количество зубов в челюсти человека. На рисунке в сагиттально-поперечном сечении череп разделен на две части. Левая сторона осталась неповрежденной и демонстрировала такие внешние структуры, как швы. Набор зубов с левой стороны отражал правильную локализацию. Правая часть была рассечена фронтальным разрезом, а верхнечелюстная пазуха обнажены. В продолжение фронтального разреза была удалена передняя часть нижней челюсти и обнажены зубы. На уровне ментального отверстия показаны компактные и губчатые костные компоненты, включая поперечное сечение через ментальное отверстие и его соединение с нижней челюстью [6]. 


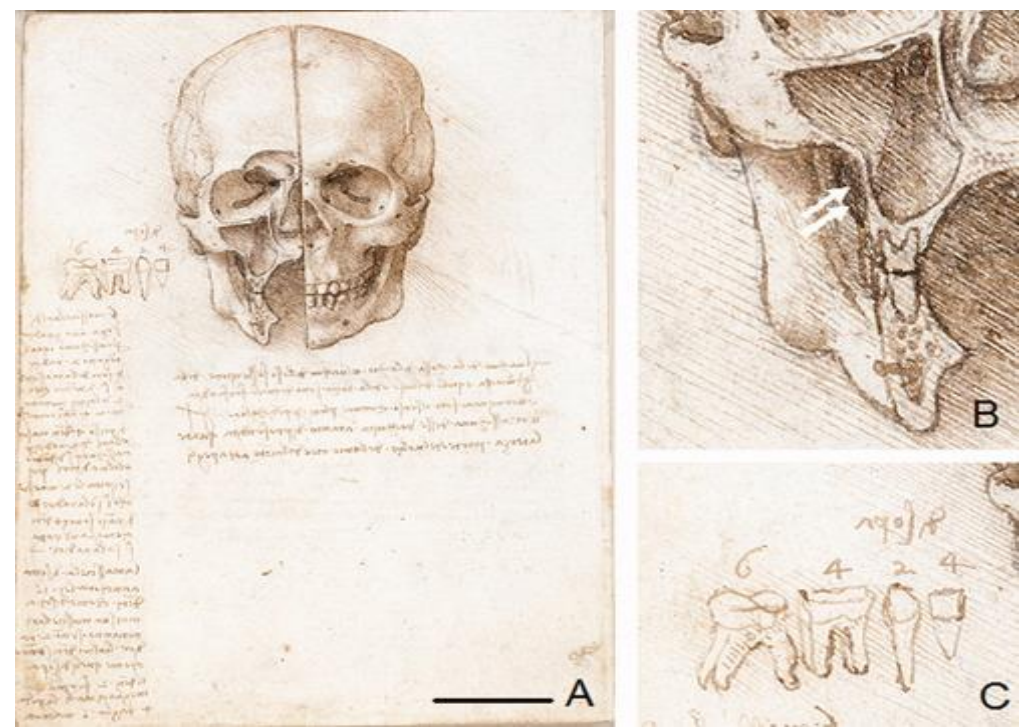

Рис. 3. «Череп в разрезе» Леонардо да Винчи. Королевская коллекция (C) 2011, Ее Величество Королева Елизавета II [6]

В связи с тем, что архив Леонардо да Винчи разошелся по разным владельцам, его анатомические зарисовки был открыты для общественности только в конце XVIII века и не смогли повлиять на развитие научной анатомии. Его изображения скелетной системы были высокого качества: несмотря на отсутствие методов визуализации высокой четкости, да Винчи смог правильно изобразить структуру позвоночного столба, анатомическую структуру костей и некоторых позвонков. Предполагалось, что именно познания ученого в области архитектуры помогли разобраться в устройстве человеческого тела. Работы Леонардо да Винчи демонстрировали изменение мировоззрения и научного взгляда на человека периода Раннего Нового времени и опережали свое время на столетия.

\section{Список литературы}

1. Jones R. (2012). Leonardo da Vinci: Anatomist. British Journal of General Practice. 62(599):319.

2. Săceleanu M.V., Mohan A. G., Marinescu A.A., Marinescu A., Ciurea A.V. (2019). Leonardo da Vinci - ingenious anatomist: 500 years since the death of the famous erudite. Romanian Journal of Morphology\&Embryology. 60(4): 13911395. 
3. Bowen G., Gonzales J., Iwanaga J., Fisahn C., Loukas M., Oskouian R.J., Tubbs R.S. (2017). Leonardo da Vinci (1452-1519) and his depictions of the human spine. Child Nerv Syst. 33:2067-2070.

4. Tubbs R.I., Gonzales J., Iwanaga J., Loukas M., Oskouian R.J., Tubbs R.S. (2017). The influence of ancient Greek thought on fifteenth century anatomy: Galenic influence and Leonardo da Vinci. Childs Nerv Syst. 34(6):1095-1101.

5. Ganseman, Y., Broos, P. (2008). Leonardo da Vinci and Andreas Vesalius; the shoulder girdle and the spine, a comparison. Acta Chirurgica Belgica. 108: 477-483.

6. Gerrits P.O., Veening J.G. (2012). Leonardo da Vinci's "A Skull Sectioned": Skull and dental formula revisited. Clinical Anatomy. 26(4):430-435. 